\title{
JPE 11-5-9
}

\section{End-Effect Compensation in Linear Induction Motor Drives}

\author{
Mohammad Reza Satvati* and Sadegh Vaez-Zadeh ${ }^{\dagger}$ \\ $\dagger^{* *}$ Advanced Motion Systems Research Lab. and Center of Excellence on Applied Electromagnetic Systems, \\ School of Electrical and Computer Engineering, University of Tehran, Tehran, Iran
}

\begin{abstract}
In this paper a control system with a high performance dynamic response for linear induction motors (LIMs) is proposed which takes into account the end-effect in both the machine model and the control system. Primary flux oriented control has two major drawbacks i.e. a lack of decoupling of the thrust and the flux and a possibility of system instability due to the end-effect. Both of these drawbacks have been dealt with in this paper. A flux estimation method is proposed to correct the flux orientation error caused by the end effect. Extensive motor performance evaluations under the proposed control system prove its superiority over conventional vector control.
\end{abstract}

Key Words: End-effect compensation, Linear Induction Motor, Primary flux oriented, Vector control

\section{INTRODUCTION}

Linear induction motors (LIMs) have gained an increasing amount of attention in recent years [1], [2]. High performance control of these motors, especially by vector control, has been presented in many works. For instance, utilizing vector control in launching aircraft has recently been considered [3]. The Vector control of LIMs has been mostly carried out in the secondary flux oriented control (SFOC) scheme [3]-[8]. The attraction of SFOC is mainly due to the fact that in this orientation the decoupling of the motor thrust and the flux can be easily achieved [9], [10]. However, a major drawback of this method is its dependency on motor parameter variations, which disrupts the flux orientation and consequently deteriorates the performance of the control system [11].

Motor parameter estimation methods have been proposed to overcome this problem [11]. However, these methods are difficult to impliment and not completely reliable. Motor parameters such as the secondary resitance and the secondary inductance change due to operating and ambient conditions. This may cuase some problems e.g. the driving motor in the flux weakening region of the SFOC need to use the secondary inductance so it can be easily inferred that the SFOC has some problem due to flux weakening. A number of researchers have addressed this problem with different methods [12][15]. Although these methods can increase the robustness of a system, they also cause difficulties such as an increased system

\footnotetext{
Manuscript received May 22, 2010; revised Mar. 14, 2011

Recommended for publication by Associate Editor Kyeong-Hwa Kim

$\dagger$ Corresponding Author: vaezs@ut.ac.ir

Tel: +98-21-61114916, Fax: +98-21-88778690, Univ. of Tehran

* Advanced Motion Systems Research Lab. and Center of Excellence on

Applied Electromagnetic Systems, School of Electrical and Computer

Engineering, University of Tehran, Iran
}

complexity and the requirement of high processor capabilities which in turn add to the system cost.

An alternative solution is a primary flux oriented control (PFOC) system that features parameter robustness and desirable dynamic performance. Despite these merits, PFOC is rarely applied to LIMs due to a lack of total decoupling of the motor thrust and the flux. In addition, the end-effect is a major dificulty in analysing and controling high speed LIMs. Recently many attempts have been carried out to conquer this inherent problem of LIM control but most of them are based on SFOC [5], [6].

The compensation of PFOC problems i.e. the end-effect and the lack of decoupling by an effective and reliable method has not yet been proposed [16]. In this paper a novel PFOC scheme has been proposed and evaluated to solve the above mentioned problems. The results obtained demonstrate satisfactory dynamic performance of the LIM under the proposed control system. The preliminary results of this research have already been presented [17].

\section{LIM MODEL}

The following sets of equations are presented as a mathematical model of LIMs [6]:

$$
\begin{gathered}
u_{d s}=R_{s} i_{d s}+R_{r} f(Q)\left(i_{d s}+i_{d r}\right)+\frac{d \lambda_{d s}}{d t}-\omega_{g} \lambda_{q s} \\
u_{q s}=R_{s} i_{q s}+\frac{d \lambda_{q s}}{d t}+\omega_{g} \lambda_{s d} \\
u_{d r}=R_{r} i_{d r} R_{r} f(Q)\left(i_{d s}+i_{d r}\right)+\frac{d \lambda_{d r}}{d t}-\omega_{s l} \lambda_{q r}=0 \\
u_{q r}=R_{r} i_{q r}+\frac{d \lambda_{q r}}{d t}+\omega_{s l} \lambda_{d r}=0
\end{gathered}
$$


where, the flux linkage components in (1)-(4) are given by:

$$
\begin{gathered}
\lambda_{d s}=L_{l s} i_{d s}+L_{m}(1-f(Q))\left(i_{d s}+i_{d r}\right) \\
\lambda_{q s}=L_{l s} i_{q s}+L_{m}\left(i_{q s}+i_{q r}\right) \\
\lambda_{d r}=L_{l r} i_{d r}+L_{m}(1-f(Q))\left(i_{d r}+i_{d s}\right) \\
\lambda_{q r}=L_{l s} i_{q r}+L_{m}\left(i_{q r}+i_{q s}\right) .
\end{gathered}
$$

In the above equations the end effect is modeled by $f(Q)$ which is represented by:

$$
f(Q)=\frac{1-e^{-Q}}{Q}
$$

where:

$$
Q=\frac{D R_{2}}{\left(L_{m}+L_{r}\right) v} .
$$

It can be seen from (10) that $Q$ reversely depends on the machine velocity $v$. Therefore, it can be assumed that the endeffect can be ignored at stand still low speeds [6].

The motor thrust is given as:

$$
F_{e}=\frac{3}{2} \cdot \frac{P}{2} \cdot \frac{\pi}{\tau}\left(i_{q s} \lambda_{d s}-i_{d s} \lambda_{q s}\right) .
$$

The state-space equation of a LIM is as follows:

$$
\dot{I}=A I+B U .
$$

The system equations of (1)-(9) in state space form are as:

$$
\begin{gathered}
I=\left[\begin{array}{c}
i_{d s} \\
i_{q s} \\
i_{d r} \\
i_{q r}
\end{array}\right], U=\left[\begin{array}{c}
u_{d s} \\
u_{q s} \\
u_{d r} \\
u_{q r}
\end{array}\right]=\left[\begin{array}{c}
u_{d s} \\
u_{q s} \\
0 \\
0
\end{array}\right] \\
A=-L^{-1} R \\
B=L^{-1}
\end{gathered}
$$

where:

$$
\begin{gathered}
R=\left[\begin{array}{cc}
R_{s}+R_{r} f(Q) & -\omega_{e} L_{s} \\
\omega_{e}\left\{l_{s}+[1-f(Q)] L_{m}\right\} & R_{s} \\
R_{r} f(Q) & -\omega_{s l} L_{m} \\
\omega_{s l}[1-f(Q)] L_{m} & 0 \\
R_{r} f(Q) & -\omega_{e} L_{m} \\
\omega_{e}[1-f(Q)] L_{m} & 0 \\
R_{r}[f(Q)+1] & \omega_{s l} L_{r} \\
\omega_{s l}\left\{l_{r}+[1-f(Q)] L_{m}\right\} & R_{r}
\end{array}\right] \\
L=\left[\begin{array}{cccc}
l_{s}+[1-f(Q)] L_{m} & 0 & {[1-f(Q)] L_{m}} & 0 \\
0 & L_{s} & 0 & L_{m} \\
l_{r}+[1-f(Q)] L_{m} & 0 & {[1-f(Q)] L_{m}} & 0 \\
0 & L_{r} & 0 & L_{m}
\end{array}\right] .
\end{gathered}
$$

Because $f(Q)$ is independent of system parameters and alters slowly with space vectors, it is assumed to be a constant.

\section{Pfoc With End-EfFect Compensation}

Fig. 1 shows a simplified block diagram of the proposed PFOC.

In primary flux oriented control $\lambda$ qs vanishes. Therefore, the thrust is simplified as:

$$
F_{e}=\frac{3}{2} \frac{\pi}{\tau_{p}} \frac{p}{2}\left(\lambda_{d s} i_{q s}\right)
$$

Also $\lambda_{d s}$ is given as:

$$
\lambda_{d s}=L_{s} i_{m s} .
$$

Thus, the thrust is proportional to the product of $i_{m s}$ and $i_{d s}$ as:

$$
F_{e}=\frac{3}{2} \cdot \frac{\pi}{\tau_{p}} \cdot \frac{P}{2}\left(i_{m s} i_{q s}^{e}\right)=k\left(i_{m s} i_{q s}^{e}\right) .
$$

In order to decouple the thrust and the flux, the magnetizing current $\left(i_{m s}\right)$, instead of the direct axis component of primary current vector $\left(i_{d s}\right)$, is used together with the quadrature axis component of the primary current vector $\left(i_{q s}\right)$. Since the primary flux is proportional to $i_{m s}$ and the motor thrust is obtained by the product of the primary flux and $i_{m s}$, it is possible to adjust the flux by adjusting $i_{m s}$ to a fixed value. The thrust is then controlled by $i_{q s}$.

Therefore, in the proposed PFOC it is sufficient to determine $i_{d s}$ from the machine model and the output of the flux controller i.e. $i_{m s}$. From Fig. 1, it can be seen that the control system consists of two major blocks i.e. the " $i_{d s}$ calculation" and the "Primary Flux \& Angle Estimation".

The " $i_{d s}$ calculation" block is depicted in Fig. 2 and is described as follows. Using (5) and (19), it is obtained as:

$$
L_{s} i_{m s}=L_{s} i_{d s}+(1-f(Q)) L_{m} i_{q s} .
$$

Also, the q-axis component of the flux linkage vector is zero.

Therefore, (6) yields:

$$
i_{q r}=-\frac{L_{s}}{L_{m}} i_{q s} \text {. }
$$

In (4) $u_{q r}$ is zero. Also the decoupling takes place in steady state condition of flux linkage. Taking these two facts into account, it is possible to write down:

$$
\lambda_{d r}=-\frac{R_{r}}{\omega_{s l}} i_{q r}
$$

The above equations yield:

$$
\begin{aligned}
i_{m s} & =\frac{L_{s}[1+f(Q)]+2 f^{2}(Q) L_{m}}{L_{s}[1+f(Q)]} i_{d s} \\
& +\frac{[1-f(Q)]}{1+f(Q)} \omega_{s l} T_{r} \sigma . i_{q s} .
\end{aligned}
$$

The primary flux estimation is carried out in the corresponding block, "Primary Flux \& Angle Estimation", as seen in Fig.1. This block is represented in Fig. 3. This synthesis is obtained by the following equations:

It is also worth mentioning that the angular velocity, $\omega_{e}$, is calculated from (2) as:

$$
\omega_{e}=\frac{u_{q s}-R_{s} i_{q s}}{\lambda_{d s}}
$$


TABLE I

LIM PARAMETERS

\begin{tabular}{|c|c|}
\hline Maximum Thrust & $1.45(\mathrm{kN})$ \\
$\mathrm{Rs}$ & $0.91(\Omega)$ \\
$\mathrm{Rr}$ & $1.13(\Omega)$ \\
$\mathrm{Ls}$ & $44.91(\mathrm{mH})$ \\
$\mathrm{Lr}$ & $42.94(\mathrm{mH})$ \\
Mass & $500(\mathrm{~kg})$ \\
\hline
\end{tabular}

resulted from (5):

$$
i_{d s}+i_{d r}=\frac{\lambda_{d s}-L_{l s} i_{d s}}{L_{m}(1-f(Q))} .
$$

It is then possible to obtain (27) with some simplifications:

$$
\frac{d \lambda_{d s}}{d_{r}}+\alpha \cdot \lambda_{s}=u_{d s}-\beta \cdot i_{d s}
$$

where:

$$
\begin{gathered}
\alpha=\frac{R_{r} f(Q)}{L_{m}(1-f(Q))} \\
\beta=R_{s}-\frac{L_{s l} f(Q)}{L_{m}(1-f(Q))} .
\end{gathered}
$$

It seems that the end effect has two major impacts on the control system. First, it causes to a decline in the effective primary resistance by increasing the velocity and secondly it results in fluctuation of the primary flux.

Fortunately, these variations are so slow in comparison with the other parameters of (27). In other words, $\alpha$ and $\beta$ are dependent on $f(Q)$ and it just increases from zero to one by a rapid increase of velocity. Since velocity is a mechanical parameter, its variations in contrast with electrical parameters is slow. Therefore, it does seem to be a very insightful approach that $\alpha$ and $\beta$ are considered as fix parameters in comparison with the flux, current and voltage of the primary. This fact simplifies (27) and makes it a linear first order deferential equation. This equation can be solved numerically and deals with the impacts of the end-effect on the monitoring of the primary flux vector. If this calculation is not performed correctly, the orientation of the flux vector in the PFOC will not be manipulated precisely. This causes system instability. This can be seen in the simulation results.

\section{EVALUATION}

\section{A. Simulation results}

In this section, extensive simulation results are presented to evaluate the dynamic performance of a LIM under a PFOC with and without end-effect compensation. The motor parameters are listed in Table I [18].

The motor performance under the control system without end-effect compensation shows a delayed response and becomes unstable as can be seen in Fig. 4. The instability of the system without end-effect compensation is shown by the thrust, flux and current trends that are depicted in Figs. 4-10.

When the velocity of the LIM increases the end-effect emerges and causes a disturbance of the orientation of the flux. This is illustrated by the d- and q-axis components of the primary flux linkage. In other words, by increasing the impact of the end-effect, the d-axis component of the primary flux linkage decreases from the nominated value and the qaxis component of the primary flux linkage increases. The graphs of the primary flux components in Fig. 6 and 7 illustrate this fact. This process affects the electrical thrust causing flux instability which in turn disturbs the LIM thrust and speed. Other variables of the motor such as the primary current and the locus of the primary flux show similar impacts as in Fig. 8,9 and 10 , respectively.

Fig. 11-19 show the system performance under the proposed control system when the end-effect is compensated. Fig. 11 shows the motor velocity command applied at 1 second. It is seen that the motor speed under the proposed control system performs well.

Fig. 12 depicts the motor thrust and load signals. The swiftness of the thrust response can be better seen in Fig. 13 and Fig. 14. Since the response of the electrical thrust to load variations is fast enough, the motor is hardly affected. As much as the electrical thrust responds rapidly, the overshoot or undershoot of the velocity is negligible. It is observed that the thrust response rise time is less than $20 \mu$ s and its settling time is less than $3 \mathrm{~ms}$.

The flux linkage components are shown in Fig. 15. It can be seen that the compensation has a substantial effect on the system stability. It can also be seen that the end-effect compensation provides an excellent flux orientation; while the system without compensation lacks a desirable flux orientation and thus becomes unstable. This fact justifies the velocity response presented in Fig 11. It is well known that the endeffect depends on the motor velocity. Therefore, at a low velocity only the flux orientation is significanly disturbed. However, at a high velocity when the end-effect becomes important the system becomes unstable unless the end-effect compensation is used.

The d- and q-axis primary current vector components under the proposed control system are also shown in Fig 16. As expected, during the transient conditions the $\mathrm{d}-$ and $\mathrm{q}$ - axis primary current vector components do not become unstable and reach the DC values in the steady-state. It demonstrates the effectiveness of proposed compensation and decoupling system. The primary phases currents are depicted in Fig. 17 and 18. The locus of the primary flux is shown in Fig. 19.

Fig. 16 shows that the motor thrust is varied by iqs and that the other current component, iqs is also adjusted to the values by which ims remains constant.

In addition, the system has been simulated with the secondary resistance and the secondary inductance increased by $20 \%$. This variation was done just in the LIM model and the control system was not changed to evaluate its robustness against parameters variations. The results showed that the trends of the velocity and the thrust have invisible changes in comparison with the previous results i.e. Fig. 11 and 12, consequently, not depicted.

Fig. 20 and 21 are the other results of the system simulation under the foregoing conditions. In comparison with Figs. 15 and 16, these graphs show little change. Fig. 20 emphasizes that the system orientation has not been impacted. This fact demonstrates the stated merits of the PFOC.

Fig. 21 shows the primary current components. In com- 


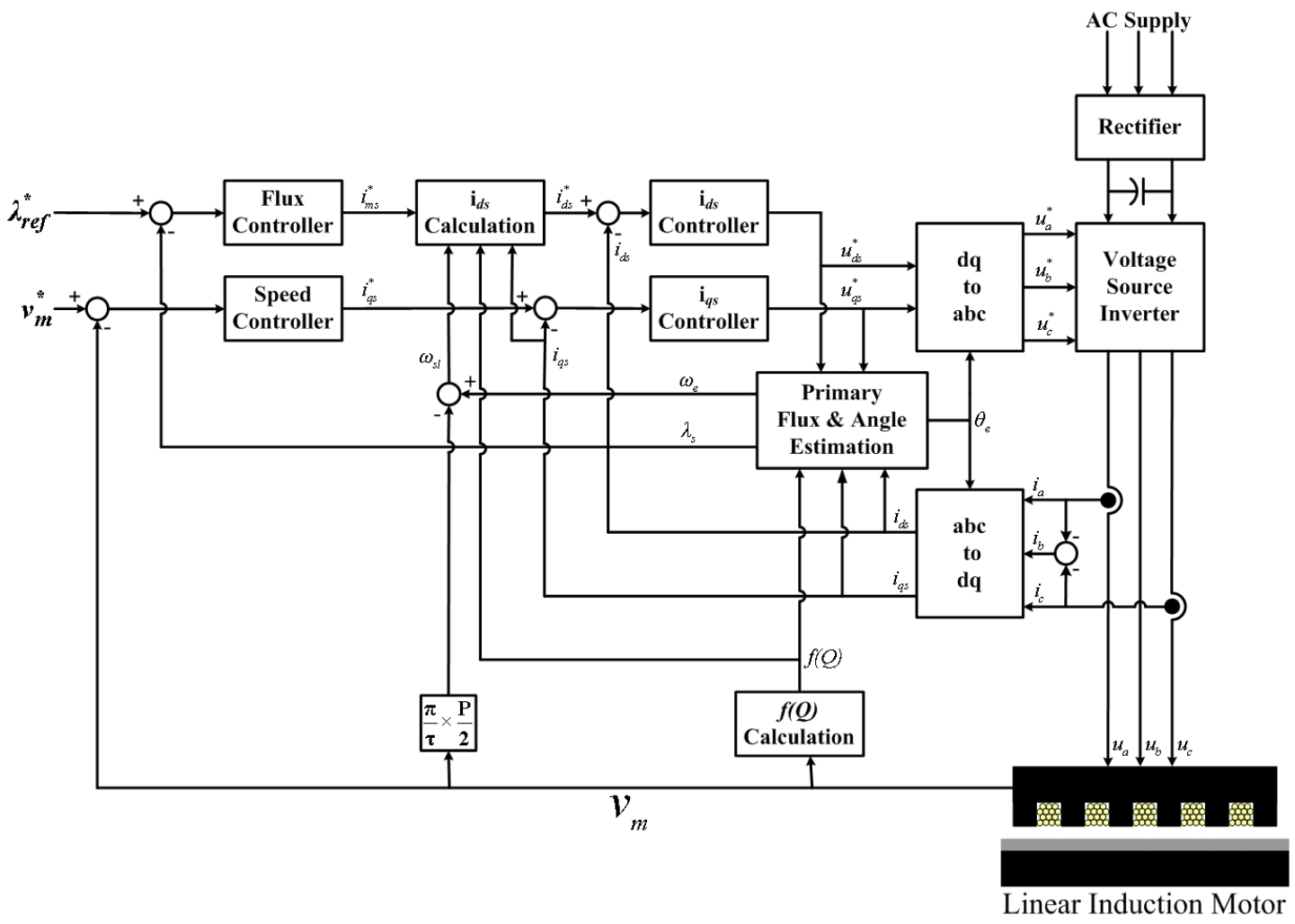

Fig. 1. PFOC block diagram with compensation of end-effect and lack of decoupling.

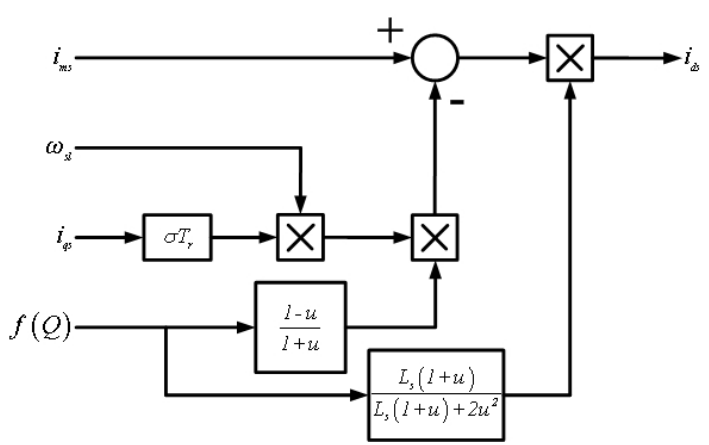

Fig. 2. Block diagram of $i_{\mathrm{ds}}$ calculation.

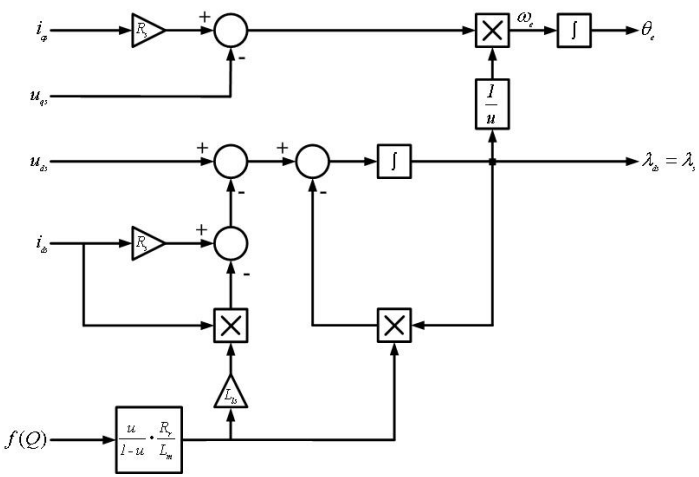

Fig. 3. Block diagram for estimation of $\lambda_{s} \& \theta_{e}$.

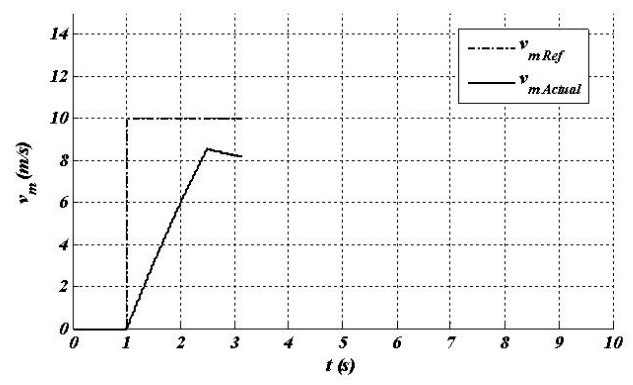

Fig. 4. Velocity of LIM without end-effect compensation.

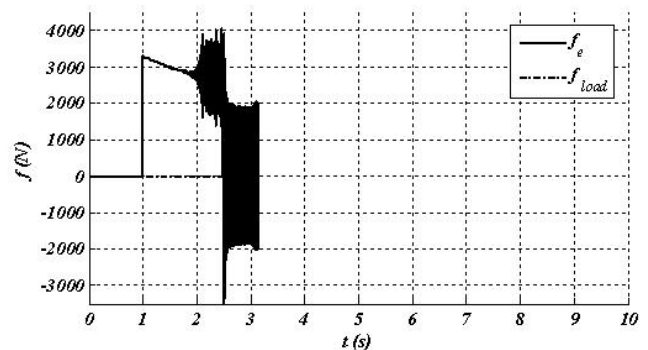

Fig. 5. Thrust of LIM without end-effect compensation.

parison with Fig. 16 the amplitude of the current has been slightly decreased. This is due to the increase in the secondary inductance.

\section{B. Comparison}

As can be seen, the proposed system kept sufficient dynamic performance and demonstrated robustness in terms of system parameters variations. As results, a comparison of the proposed 


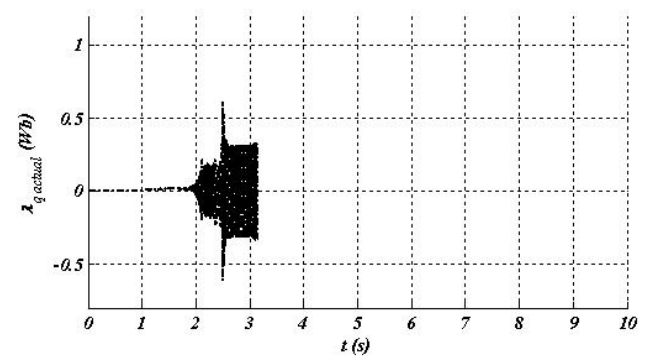

Fig. 6. q- axis primary flux component of LIM without end-effect compensation.

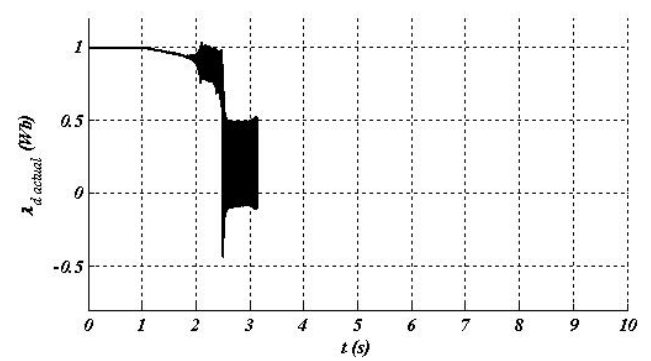

Fig. 7. d- axis primary flux component of LIM without end-effect compensation.

system and a conventional SFOC is summarized in the table II.

The lack of thrust and flux decoupling has been compensated for and the good performance of the PFOC has been evaluated. Consequently, both systems i.e. the PFOC and the SFOC have been decoupled. As a results, the PFOC dynamic performance as good as the SFOC.

The end effect is known as a main challenge of LIM control systems. Some methods for governing such strange phenomenon are addressed but most of them are for SFOC. The end effect was compensated for in the PFOC in this paper on the first try.

The main advantage of the PFOC, demonstrated in this paper, is its robustness against the LIM secondary parameters. On the other hand, it is a main demerit of SFOC.

The dependency on secondary parameters in the SFOC causes system instability or at least a decline in its performance. It also causes another defect i.e. difficulties in controlling the motor in the flux weakening region. This is due to its need to use the inductance of the secondary.

\section{CONCLUSION}

In this paper a number of difficulties associated with the primary flux oriented control of LIMs i.e. the end effect and the coupled thrust and flux are addressed and a novel primary flux

TABLE II

COMPARISON

\begin{tabular}{|c|c|c|}
\hline Features & SFOC & PFOC \\
\hline $\begin{array}{c}\text { Decoupling of flux and } \\
\text { thrust }\end{array}$ & $\begin{array}{c}\text { inherently } \\
\text { decoupled }\end{array}$ & $\begin{array}{c}\text { Successfully } \\
\text { decoupled }\end{array}$ \\
\hline $\begin{array}{c}\text { System dynamic } \\
\text { performance }\end{array}$ & good & good \\
\hline $\begin{array}{c}\text { End effect compensation } \\
\text { pependency on secondary } \\
\text { parameters }\end{array}$ & Required & Required (done) \\
\hline $\begin{array}{c}\text { Flux weakening capability } \\
\text { has some } \\
\text { difficulties }\end{array}$ & $\begin{array}{c}\text { Easily can be } \\
\text { achieved }\end{array}$ \\
\hline
\end{tabular}

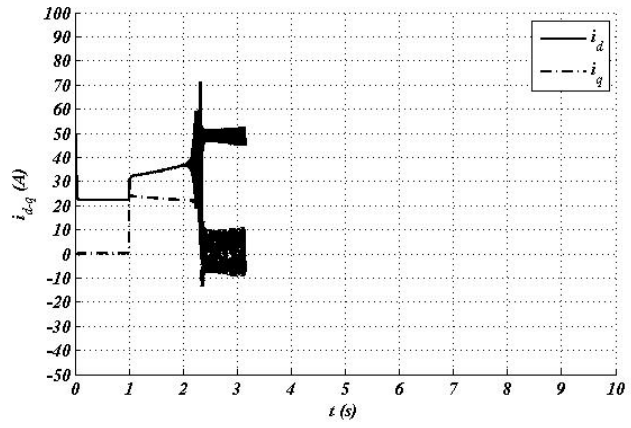

Fig. 8. primary current component of LIM without end-effect compensation.

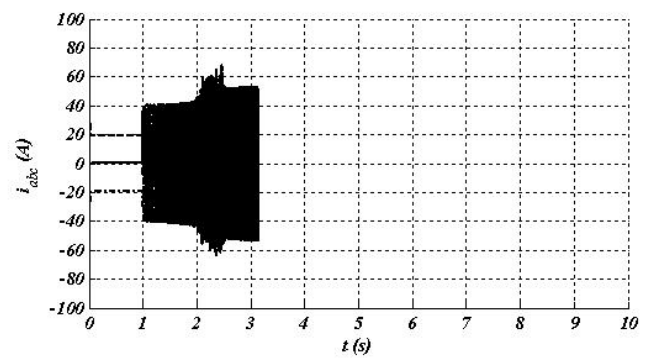

Fig. 9. primary current of LIM without end-effect compensation.

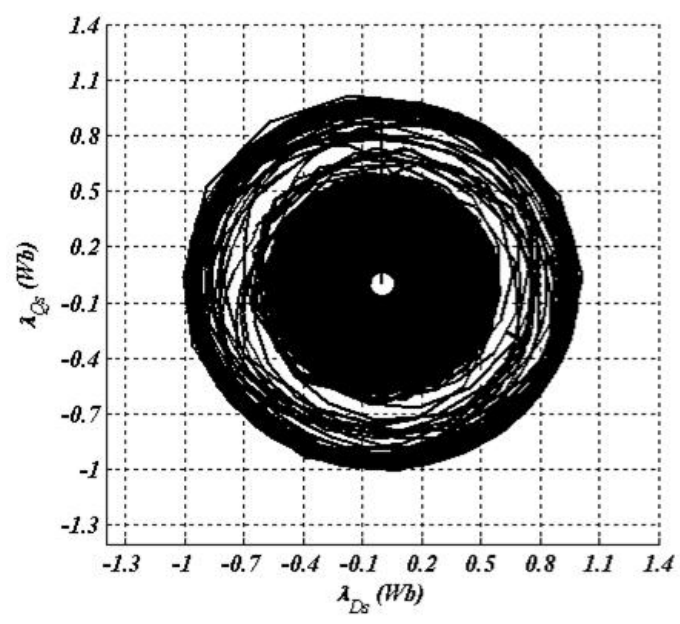

Fig. 10. Primary flux locus of LIM without end-effect compensation.

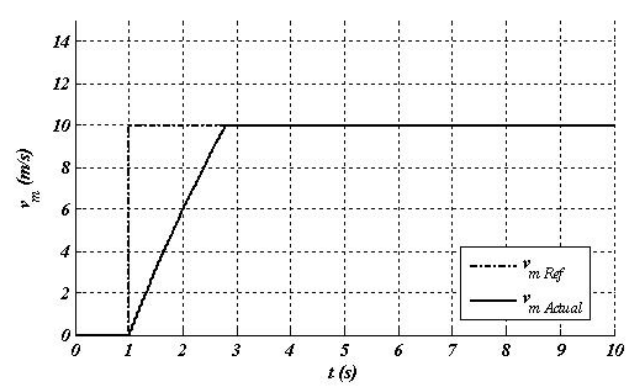

Fig. 11. Velocity of LIM with end-effect compensation. 


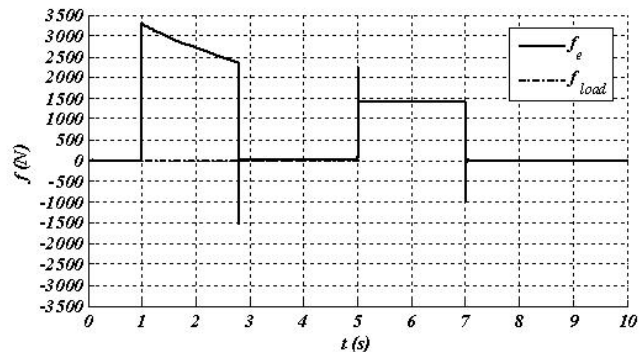

Fig. 12. Thrust of LIM with end-effect compensation.

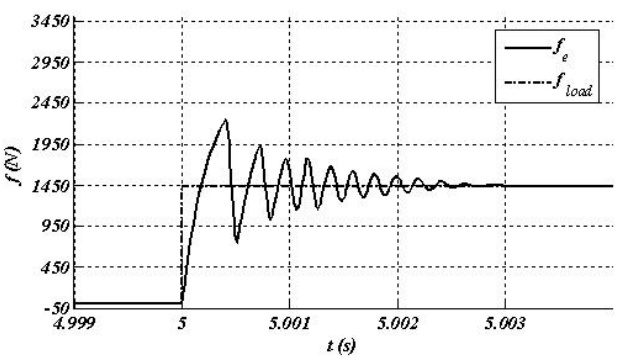

Fig. 13. Thrust of LIM when with end-effect compensation.

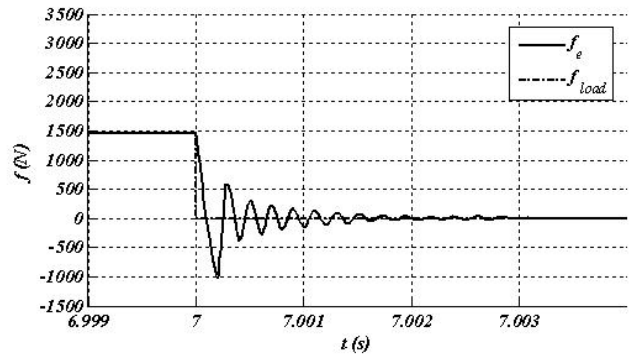

Fig. 14. Thrust of LIM with end-effect compensation.

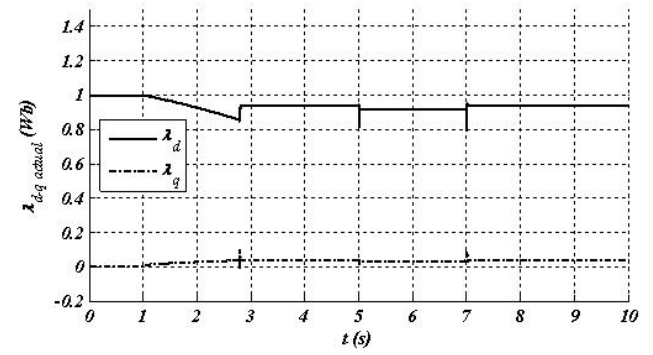

Fig. 15. Primary flux component of LIM with end-effect compensation.

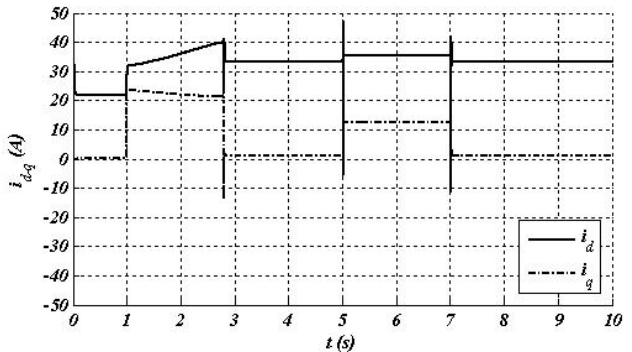

Fig. 16. primary current component of LIM with end-effect compensation.

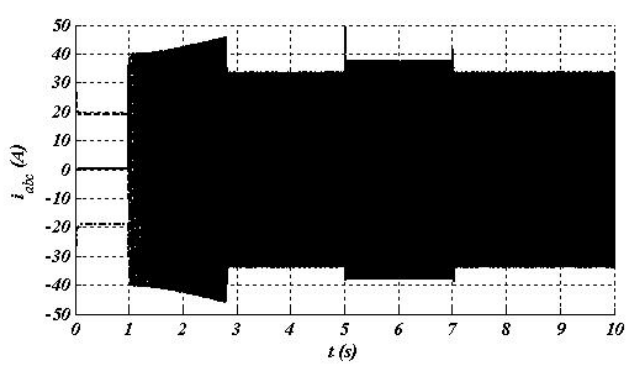

Fig. 17. Primary current of LIM with end-effect compensation.

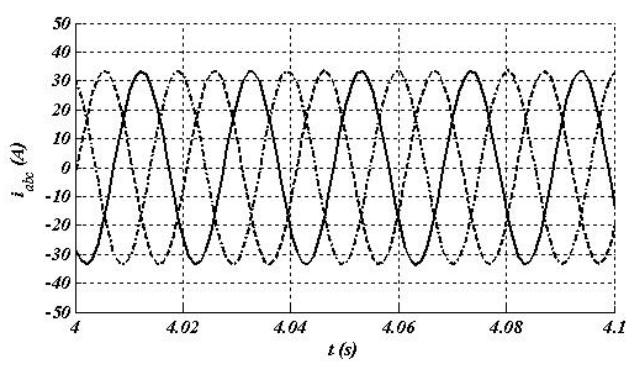

Fig. 18. Primary current of LIM with end-effect compensation.

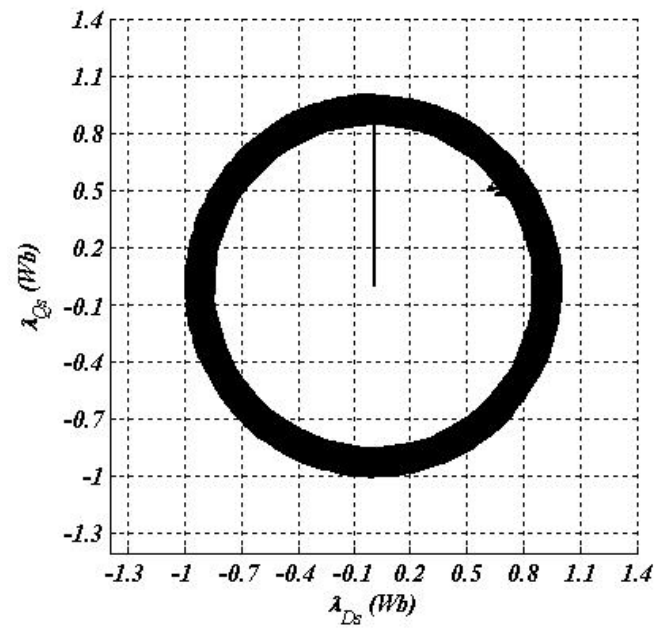

Fig. 19. Primary flux locus of LIM with end-effect compensation.

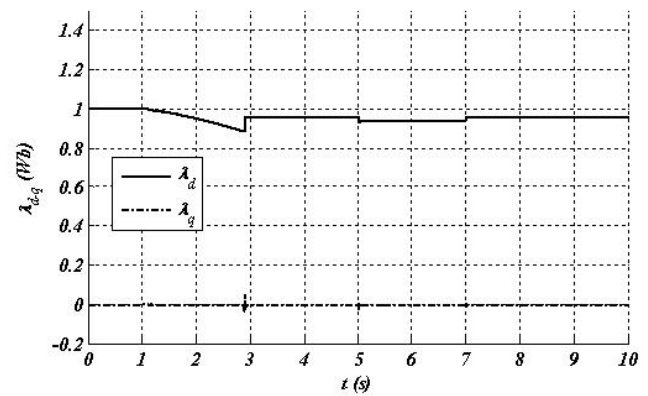

Fig. 20. Primary flux component of LIM with increment of $\% 20$ in secondary parameters under the proposed control system. 


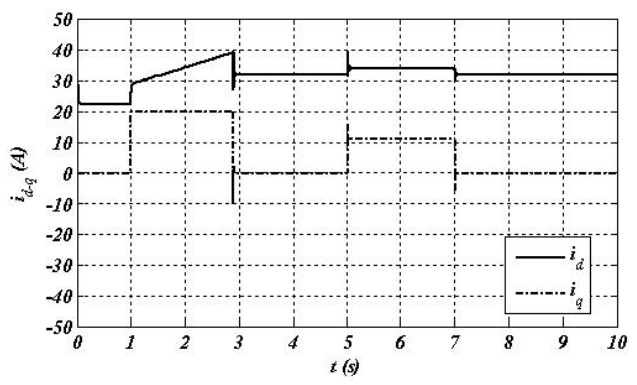

Fig. 21. Primary current component of LIM increment of $\% 20$ in secondary parameters under the proposed control system.

oriented control system is proposed to overcome the parameter dependency of secondary flux oriented control. The proposed system provides desirable decoupling between the flux and the thrust. It also presents an end-effect compensation scheme for accurate orientation of the rotating reference frame along the primary flux linkage. LIM performance under primary flux oriented control has been compared with performance under secondary flux oriented control and the partial superiority of the former is confirmed. Also the motor performance under the proposed control system with and without end effect compensation is presented to show a substantial gain when the compensation is performed.

\section{REFERENCES}

[1] S. A. Nasal and L. Bolder, Linear Motion Electric Machines, John Wiley, 1976.

[2] J. F. Gyres, Linear Induction Drives, CityOxford U.K.: New Clarendon, Press, 1994.

[3] D. C. Meeker and M. J. Newman, "Indirect vector control of a redundant linear induction motor for aircraft launch," in Proceeding of the IEEE, Vol. 97, No. 11, pp. 1768 - 17762009.

[4] E. F. da Silva, E. B. dos Santos, P. C. M. Machado, and M. A. A. de Oliver, "Vector control for linear induction motor," in Proc. ICIT'03, pp. 518 - 523, Dec. 2003

[5] E. F. da Silva, C. C. dos Santos, J. W. L. Nerds, "Field oriented control of linear induction motor taking into account end-effects," in Proc. AMC'04, pp. 689-694, Mar. 2004.

[6] J. H. Sung and K. Nam, "New approach to vector control for a linear induction motor considering end effects," in Proc. IAS Annual Meeting, pp. $2284-2289$, Oct. 1999.

[7] Z. Mingy an, M. Weaning, X. Jin, and L. Web, "Vector control for the linear induction motor based on the position closed-loop", in Proc. ICECE, pp. 2515-2518, Jun. 2010,

[8] W. Yuhua and G. Kang, "Speed and rotator magnetic flux close loop vector control system for the linear induction motor based on neuron adaptive controller," in Proc. MASS '09, pp. 1 - 5, Oct. 2009.

[9] W. Leonhard, Control of Electrical Drives, Springer, 3rd Edition, 2001.

[10] P. Vas, Vector Control of AC Machines, Oxford Clarinda Press, 1994.

[11] A. Ghastly, "12 Conductors of a linear induction motor," IEEE Transactions on Energy Conversion, Vol. 13, No. 2, pp. 111-116, Jun. 1998.

[12] P. Liu, C. Y. Hung, C. S. Chiu, and K. Y. Lian, "Sensorless linear induction motor control using fuzzy observers for speed tracking," in Proc. ICECE, pp. 5621-5626, May 2010.
[13] F. J. Lin, P. K. Huang, and W. D. Chou, "Recurrent-fuzzy-neuralnetwork-controlled linear induction motor servo drive using genetic algorithms," IEEE Trans. Ind. Electron., Vol. 54, No. 3, pp. 1449-1461, Jun. 2007

[14] F. J. Lin, C. K. Chang, P. K. Huang, "FPGA-based adaptive backstepping sliding-mode control for linear induction motor drive," IEEE Trans. Power Electron., Vol. 22, No. 4, pp. 1222-1231, Jul. 2007.

[15] K. Y. Lian, H. C. S. Chiu, and 1. C. Fu, "Robust adaptive control of linear induction motors with unknown end-effect and secondary resistance," IEEE Trans. Energy Convers., Vol. 23, No. 2, pp. 412-422, Jun..2008.

[16] A. Gastli, "Improved field oriented control of an LIM having joints in its secondary conductors", IEEE Trans. Energy Convers., Vol. 17, No. 3, pp. 349-355, Sep. 2002.

[17] S. Vaez-Zadeh, and M. R. Satvati, "Vector control of linear induction motor with end-effect compensation," in Proc. ICEMS '05, pp. 635 638, Sep. 2005

[18] J. Kim, B. G. Gu, G. Kang, and K. Nam, "Attractive force reducing strategy of LIM for PRT systems," in Proc. IEMDC'03, pp. 1832 -1836, Jun. 2003.

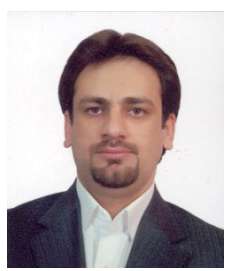

Mohammad Reza Satvati was born in Tabriz, Iran, in 1978. He received his B.S. from the Azad University of Tabriz, Tabriz, Iran, in 2000 and his M.S. from the University of Tehran, Tehran, Iran, in 2005, both in Electrical Engineering. He has been working in the oil, gas and petrochemical industries since 2005 where he is now with the OIEC group. His research interests include the design, modeling and control of electrical machines, and the electrical system of industrial plants.

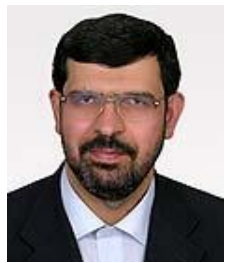

Sadegh Vaez-Zadeh received his B.S. from the Iran University of Science and Technology, Tehran, Iran, in 1985 and his M.S. and Ph.D. from Queen's University, Kingston, ON, Canada, in 1993 and 1997, respectively, all in Electrical Engineering. He was with several research and educational institutions in different positions before joining the University of Tehran in 1997 as an Assistant Professor, where went on to become an Associate Professor in 2001 and a Full Professor in 2005. He served the university as the Head of the Power Division from 1998 to 2000. He is currently the Director of the Advanced Motion Systems Research Laboratory which he founded in 1998 and he has been the Director of the Electrical Engineering Laboratory since 1998. His research interests include advanced rotary and linear electric machines and drives, magnetic levitation, electric and hybrid vehicles, power system control and policy making. He has published over 150 technical papers in these areas including about 40 journal papers and he holds a US patent. Prof. Vaez-Zadeh is a Senior Member of the IEEE, a member of the IEEE PES Motor Sub-Committee and the Power System Stability Control Sub-Committee. He is an Editor of the IEEE Transactions on Energy Conversion and a founding member of the editorial board of the Iranian Journal of Electrical and Computer Engineering. He is also a member of the editorial board of the Journal of Faculty of Engineering, which is the oldest engineering journal in the Middle East, and a member of the editorial board of the International Journal on Power System Optimization. He has been active in IEEE sponsored conferences as a general chair, a member of technical and steering committees, a session chair, etc. He has received a number of awards domestically and internationally including a best paper award from the Iran Ministry of Science, Research and Technology in 2001 and a best research award from the University of Tehran in 2004. He has also received an International Khwarizmi Award and first prize from the Commission on Science and Technology for Sustainable Development in the South (COMSATS) in 2011. 